\title{
Seafarers' attitude and cultural adaptation influencing the work motivation during the time of pandemic
}

Rayos, Juanda Lee T. $\triangle$

Lyceum of the Philippines University Batangas, Philippines (jlee.rayos81@gmail.com)

Borbon, Noelah Mae D.

Lyceum of the Philippines University Batangas, Philippines (nmdborbon@lpubatangas.edu.ph)

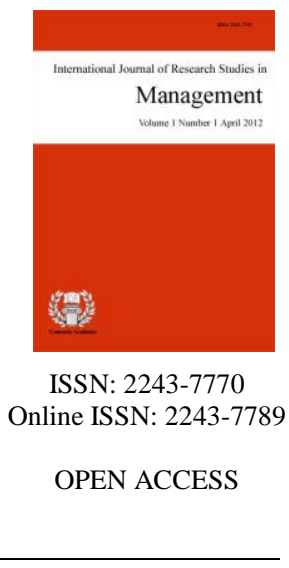

Received: 9 November 2021

Revised: 28 February 2022

Accepted: 4 March 2022 DOI: $10.5861 /$ ijrsm.2022.17

\section{Abstract}

Seafarers' jobs and living onboard as well as their mental health have been affected by the pandemic. These are indeed characteristics that may have a positive impact on seafarers, preventing them from quitting their jobs onboard. But, it is believed that on the other hand, there may also be influencing factors that make other seafarers remain still and firm in the performance of their work. The study aimed to determine attitude and cultural adaptation influencing the seafarers' work motivation of the seafarers in cruise line vessel such as attitude towards work environment as to the physical setting, emotional setting and social setting, culture adaptation in terms of communication skills and interpersonal relationship and work motivation in terms of the reward system and welfare and opportunity. Correlational design was applied to determine the relationship between the respondents' demographic characteristics and their attitude and culture adaptation and if attitude and culture adaptation influence their motivation to stay on their work. The participants in the study were 385 seafarers who work in the sections on food and beverage, housekeeping, hotel administration, and deck and engine department. Most of the respondents are $26-41$ years old and married, male-dominated, and working onboard for more than 10 years. They often observed work attitudes towards work environment, cultural adaptation, through communication skills and interpersonal relationships, and they are often motivated by reward system and welfare and opportunity. It is implied that competitive salaries, a comfortable workplace environment, a reward system, and welfare and opportunity for career progression may motivate the seafarers to stay on their job. Also, training on crisis management may help prepare future seafarers to be ready to adapt to life onboard ships.

Keywords: attitude, cultural adaptation, motivation, seafarer, pandemic 


\section{Seafarers' attitude and cultural adaptation influencing the work motivation during the time of pandemic}

\section{Introduction}

Previously, sailing was thought to be a life-long vocation with a hierarchical system to the work, living, and functions on board. However, attitudes toward the durability of the maritime career have altered, and it is no longer thought to be a job for life for the majority. There are those who stay in the job and there are those who leave and quit. According to several studies, seafarers from nations such as the Philippines, the United Kingdom, Ecuador, and Taiwan chose sailing because of the 'excellent pay' (Talmor, 2020). Filipinos are frequently driven into the seafaring sector due to a lack of alternative career options ashore. Seafarers who do not intend to stay and create a "profession" in the seafaring sector may depart after a few years. Some people view seafaring as a temporary situation in their lives, with the goal of working for a short time until they have saved enough money to achieve a specific set of goals.

The Philippines is one of the major outstanding sources of seafarers in the world. At any one moment, at least 400,000 Filipinos have employed onboard ocean-going boats such as bulk carriers, cargo ships, tankers, and passenger ships, the majority of which are cruise ships. More than a fourth of the world's sailors come from the Philippines. In 2019, those 380,000 Filipino sailors added to the Philippine economy. Yet, throughout recent months since the beginning of the Coronavirus, 19 pandemic 50,000 Filipino sailors have been localized. According to POEA Administrator, Bernard Olalia, in May 2021 some 30000 seafarers had been deployed to different destinations (Patinio, 2021). The cruise sector is now the most interesting and fastest-growing section of the global tourism business (Gibson \& Parkman 2019).

As discussed by Smith (2018), working onboard may sound appealing, but seafaring is not for everyone. But even though they pay for their own accommodation and living expenses, their pay is often minimal; nonetheless, tips might supplement their earnings. While it is tempting to tour the world, it is unlikely to be a vacation because employees work long hours and have few days off. Seafarers must adjust to living in cramped quarters, making it difficult to maintain a good work-life balance since they are confined to the ship most of the time because they do not have the opportunity to return home (Cantindig, et al 2019). After several years, those seafarers still had no interest in staying in the maritime sector and making a 'career.' Some people consider burning to be a phase in their lives that will eventually pass. And their plan is to labor for a limited time until they acquire enough money to accomplish a set of goals. Another cause for leave might be seafarers' inability to deal with the demanding working circumstances onboard. These includes differences, constant stress, and high workloads.

Thousands of seafarers have been requested to extend their contracts beyond their typical tour of duty due to the COVID19 outbreak, and some have chosen to stay onboard to proceed. However, there are some seafarers who had got "stuck" on board. This is also referred to as the "golden handcuffs" phenomenon, in which seafarers acquire acclimated to greater wages that they would not normally be able to earn elsewhere. Despite extremely lucrative employment offers, an adventurous working environment, and a "globetrotting" lifestyle, most seafarers, according to Raunek (2019), abruptly abandon their ship occupations by taking chances ashore. Unsettled lifestyle, hectic life, onboard politics, lack of social life, being away from the family, personal/family problems, rise in maritime piracy, health issues, reducing shore leaves, lack of shore jobs, reducing crew members, and stringent maritime laws are among the main reasons they quit their jobs, according to him. This practice is gaining traction and can now be found in a number of countries of the globe.

International trade and the global economy rely heavily on seafarers. The maritime industry's long-term viability is dependent on the availability of appropriately skilled seafarers and the capacity to recruit a sufficient 
Seafarers' attitude and cultural adaptation influencing the work motivation during the time of pandemic

number of newcomers. Seafaring has different qualities from other vocations, notably in terms of living and working circumstances. According to a recent industry research, nearly 1.6 million seafarers work on ships such as tankers, bulk carriers, container ships, and passenger ships. According to the International Transport Workers' Federation (ITF), the cruise ship industry employs between 300,000 and 350,000 seafarers (Geneva, 2019). In the cruise liner business, sea-based occupations are in high demand, and shipping firms all over the world are announcing their staffing requirements (Scout Cruise).

This study is founded on four significant theories that have bearing on the investigation of the three variables: Kellman's Theory of Attitude Organization, Sverrre Lysgarrd U-curve model of Cultural Adaptation Theory, Incentive Theory of Motivation, and Hezberg's two-factor theory. Heider's balancing theory is based on Kellman's (2015) Theory of Attitude Organization (Learning Theory that claims a person's behaviours are founded on principles of reinforcement, emulation, and discipline) (2015). He recognized three basic types of influence processes, which he named compliance, identification, and internalization. When a person accepts influence in the hopes of receiving a favorable response from another person or group, this is known as compliance. He conforms to the induced behavior not because he believes in its substance, but because he expects to get certain incentives or approbation in exchange for conforming. When a person accepts influence in order to form or sustain a gratifying, self-defining connection with another person or group, this is referred to as identification. Because the induced behavior is linked to the desired connection, he adopts it. Internalization happens when a person accepts influence because the induced behavior's substance, the thoughts and acts that make it up, are intrinsically satisfying. This type of behavior is more likely to be integrated with the individual's established values. Seafarers' attitude may be influenced by their hopes to achieve a favorable reaction from peers and from the manager, gain rewards or approval. Also, they may have the desire to establish and maintain a satisfying relationship with the people they work with and lastly, because they are influenced by their existing values.

Incentives in workplaces, like other aspects of life, may have both positive and negative aspects. Positive incentives are considered in this context. Positive incentives provide employees the certainty that they will get something they want in return for performing well. Incentives in the form of rewards, recognition and opportunities are influential factors that will work to retain the seafarers. The pandemic crisis has impacted the life of job and life onboard for seafarers, and also their mental wellbeing and tiredness. These are indeed variables that may help to lessen the pandemic's detrimental effects, but it is believed that on the other hand, there may also be influencing factors that make other seafarers to remain still and firm in the performance of their work. In the study conducted by Pauksztat et al. (2020), among the 671 seafarer respondents, majority of them reported that the epidemic had an influence on personnel changes and ship-to-shore relations. In terms of how the pandemic has impacted their employment, non-work life on board, and availability to supplies, respondents' perspectives were different. However, on the other hand, there may be others who had withstood the impact that they were able to cope with the situation and managed to perform their work. This situation challenges the researcher to investigate the factors that motivate the seafarers to continue performing their work. And it might be helpful for the future career in the maritime and seafarers that might indulge in this line of profession, it may be helpful to include in the training crisis management on board.

Objectives of the study - This research examined the attitude and cultural adaptation influencing the seafarers' work motivation. Specifically, it aimed to identify the respondents' characteristics in terms of age, sex, civil status and length of service; determine the attitude towards work in their physical setting, emotional setting and emotional setting; determine how they adapt to the culture in their work environment through communication skills and interpersonal relationship; determine their motivation through reward system and welfare and opportunity; and test the significant differences on the responses when grouped according to profile.

\section{Methodology}

Research Design - This study utilized descriptive design. Descriptive research, according to Gay et al. 
(2018), entails gathering data in order to answer questions, as well as determining and reporting the current state of affairs. It describes the characteristics of the respondents as to their age, sex, civil status and length of service. Furthermore, it describes their attitude in work environment in different settings, how they adapt culturally, and the motivation that makes them retain their work aboard cruise ship. It involves conducting of survey using quantitative variables.

Participants of the Study - The participants in the study were 385 seafarers who work in the sections on food and beverage, housekeeping, hotel administration and deck, and engine department. Seafarers who are currently working on board and on vacation because of the pandemic are included in the study. As a sample 385 cruise employees was utilized in accordance with the Raosoft Sample Size Calculator considering the 5\% margin of error and $95 \%$ confidence level. The study was conducted online particularly to Filipino employees working on board on the passenger ships and on vacation during the pandemic. sampling technique was used in selecting samples because not all seafarers currently working on board cruise ships and on vacation would be chosen to participate in the study. All seafarers working on the merchant ships including those who work in the hotel as housekeepers, chefs, waiters/ waitresses, hotel administrators, and deck were selected as samples. However, due to the constraints amidst pandemic such as the absence of face-to-face contact, access to administer personally the instrument, limited time, and willingness of the target respondents, the sample became limited to 385 seafarers. Only those who answered the instrument online were considered samples of the study.

Data Collection Instrument - The researcher used a survey questionnaire in Google form which was adaptive and modified. It is composed of items that are aligned to the objective and specific problems of the study. The questionnaire was divided into four component parts: Part 1 is a survey on the demographic characteristics of the respondents such as age, sex, civil status and length of service; Part 2 contained items about attitude towards work environment in physical setting, emotional setting and social setting; Part 3 comprised items on culture adaptation indicated by communication skills and interpersonal relationship; and Part 4 composed of items about work motivation indicated by reward system and welfare and opportunity. The items in the questionnaire are adapted from Mejia, (2021) and modified which are based on literature reviewed. They were checked by the researcher's adviser and validated by the university statistician. For validation, items in Part 2, 3 and 4 were subjected to Cronbach's Alpha Test. All Cronbach's Alpha Values were rated Excellent: ( $a \geq$ 0.9) Attitude Towards Work Environment: Physical Setting $=0$ 920, Emotional Setting $=0.907$ and Social Setting= 0.936. Culture Adaptation: Communication Skills - 0.924, Interpersonal Relationship - 0.937 Work Motivation: Reward System - 0.911, welfare and Opportunity - 0.962

Data Gathering Procedure - To be able to gather data needed for the study, survey questionnaire was utilized to answer the research question. The researcher personally mailed the questionnaires to the respondent aboard the ship and seafarers on vacation. The researcher sought permission from the ship captain of the several ships and crewing manager on land for the data gathering. Consent of the respondents were also sought before the conduct of the study. The study was conducted on September 1, 2021 until September 30, 2021. Survey questionnaire in Google Form was sent to the respondent of the study. Along with the questionnaire is a letter of request for the respondent to take part in the research. The respondents were guaranteed that their responses would be kept private. Instructions and items in the questionnaire were carefully explained. The researcher checked the accomplished and submitted forms daily from the start of the administration of the questionnaire until the last day. The respondent was guaranteed of the anonymity and respect for their responses by the researcher. Because the researcher trusted their honesty in answering the survey, the respondent was given the choice of remaining anonymous. Upon retrieval of the questionnaire, the responses were reviewed, coded, tailed and tabulated.

Data Analysis - The following statistical tools were used to conduct data analysis. The demographic profile of the respondents was presented using frequency and percentage distribution. Weighted Mean and Ranking were used to assess the performance of the seafarers in terms of knowledge, skill and attitudes; as well as to determine the work motivation in terms of rewards system and welfare. To determine significant differences, the 
Seafarers' attitude and cultural adaptation influencing the work motivation during the time of pandemic

results of the Mann-Whitney $U$ test for two groups will be employed as part of the non-parametric testing. Furthermore, all data were handled with PASW version 26 statistical software to better understand the study's results that used an alpha level of 0.05 . The collected data were treated to statistical analysis and interpretation with the use of statistical tools Percentage was used to determine the proportion of the respondents in their demographic characteristics. Weighted mean was used to calculate the average responses of the respondents in each item in the questionnaire on the seafarers' attitude towards environment, culture adaptation and work motivation. ANOVA or analysis of variance was used to analyze the difference among means of variables at 0.5 significance level. To evaluate substantial differences, the Mann-Whitney $U$ test results for two groups were employed as part of the non-parametric testing. Furthermore, all data were handled with PASW version 26 statistical software to better understand the study's results at an alpha level of 0.05 .

Ethical Consideration - The respondent was guaranteed anonymity and respect for their responses by the researcher. The researcher was confident in their ability to answer the survey honestly, so he gave respondents the option of remaining anonymous. To continue and regulate ethics in conducting this research, the researcher observed the following: Any private information relating to the cruise seafarers such as their names and trivial information will not be mentioned in any part of this research. The respondents were not forced to answer the questionnaire. Appropriate document sourcing and referencing were done to promote copyright laws. Private information of the seafarers such as their names are regarded with utmost confidentiality. Together with the electronic questionnaire, a letter was sent to them to secure permission before they provided the data. The researcher explained the research tool for clarity and they were not forced to answer the questionnaire. The searcher sought permission and approval from the author instrument to adapt and modify and assure that it would only be used for the aim of study.

\section{Results and Discussion}

Table 1

Percentage Distribution of the Respondents Profile

\begin{tabular}{|c|c|c|}
\hline Age & Frequency & Percentage (\%) \\
\hline 25 years and below $($ Gen $Z)$ & 30 & 7.80 \\
\hline $26-41$ years old $($ Gen $Y)$ & 169 & 43.90 \\
\hline $42-56$ years old $(\mathrm{Gen} X)$ & 149 & 38.70 \\
\hline 57 years old and above (Baby Boomers) & 37 & 9.60 \\
\hline \multicolumn{3}{|l|}{ Sex } \\
\hline Male & 334 & 86.80 \\
\hline Female & 51 & 13.20 \\
\hline \multicolumn{3}{|l|}{ Civil Status } \\
\hline Single & 110 & 28.60 \\
\hline Married & 275 & 71.40 \\
\hline \multicolumn{3}{|l|}{ Length of Service } \\
\hline 1 year and below & 19 & 4.90 \\
\hline $2-5$ yrs & 90 & 23.40 \\
\hline $6-9 \mathrm{yrs}$ & 31 & 8.10 \\
\hline $10 \mathrm{yr}$ and up & 245 & 63.60 \\
\hline
\end{tabular}

Table 1 presents the percentage distribution of the respondents' demographic profile as to their age, sex, civil status, and length of service in the seafaring job. The study reveals that the millennial generation are more motivated and mature in handling tasks. The findings show that many respondents are $26-41$ years old (43.90\%). This finding is not consistent with the finding of Ayap and Macalalad, (2016) in which the majority of the seafarers are 23 - 27 years old (44.20\%). Most seafarers belong within the late early adulthood or young adults and middle adulthood in human life development. This is the age of peak physiological development that can be considered the physically strongest among the groups in the adulthood stage. Based on their age, they are capable of performing tasks related to seafaring jobs. They may already be adjusted to their work environment, have experienced challenges and difficulties that they have won over and resolved. They are even more skillful 
than at an earlier age when they joined the seafaring job.

However, the age group with the least number of workforce is 25 years old and younger (7.80\%) while in the study of Ayap and Macalalad, (2016), the oldest group of 48 years old and above (8.40\%) are the least number. At this younger age, individuals are thinking of new possibilities. It is the period when they adjust to new patterns of life in terms of jobs. It is also the beginning where they develop patterns of behavior and attitudes which they learn from their working environment. According to Psychology course provider Lumen Learning (2018), people in their twenties and thirties are often referred to as early adults and spend a lot of energy focusing on the future and making decisions that influence them. It's time to spend. She helps her make money with a fulfilling adult life status. Late 30s (or 40s) In the mid-60s, it is called middle age. During this time, many people are at the peak of labor productivity. It may be time to acquire specific discipline expertise, understand problems, find solutions, and improve efficiency.

Results show that the respondents are dominated by male $(86.80 \%)$ and female respondents are only 13.20 percent. This finding is consistent with the finding of Ayap and Macalalad, (2016) in which males are the majority group comprising $92.20 \%$. This shows that seafaring is a male dominated industry. In older times, a man working on board was called seaman However, the word seafarer has replaced the term "seaman" because women have been taking part in this industry. There are few women attracted to this job because of the general challenges of weather, hard work and rough seas which women may not withstand. Also, opportunities for promotion for women seafarers are limited. Based on the results presented in the table, majority of the respondents are married $(71.40 \%)$ and only $28.60 \%$ are single. This is contrary to the finding of Ayap and Macalalad, (2016) in which the seafarers slightly outnumbered (51.90\%) the married ones. High income in seafaring job attracts more married individuals to engage in this maritime industry. According to payscale.com, seafarers with 5-9 years of experience earn Php749,000 a year exclusive of bonuses and tips. This is a motivation to married seafarers to work on sea because with this income, they can provide better life to their families.

As to the length of service, a great percentage said (63.60\%) they have been working on board for 10 years and more. Only $4.90 \%$ have been working for 1-year and less. Despite the 12-month contract with a company, seafarers continue to work onboard by applying to another company. After the contract, they usually stay with the family for two months and undergo training for employment in another company. As a general rule, the terms of employment of seafarers and companies are mutually agreed but cannot exceed 12 months. The contract ends when the seafarer ends the contract on board, unregisters and arrives at the airport or port of the employer. Any extension or the contract can be voluntary or compulsory. Extensions are usually not recommended for fatigue, self-satisfaction, and other health reasons. Also, if facilitation has already been implemented, it will not be accepted. Extensions are required due to port and airport restrictions (Gorecho, 2020).

\section{Table 2}

Attitude Towards Work Environment Aboard the Ship in Terms of Physical Setting

\begin{tabular}{|c|c|c|c|}
\hline Indicators & Weighted Mean & Verbal Interpretation & Rank \\
\hline Provides me with less rigid elements on physical arrangement & 3.95 & Often & 10 \\
\hline Encourages quality of work and promotes work efficiency & 4.64 & Always & 3 \\
\hline Helps me better appreciate standard work performance & 4.67 & Always & 2 \\
\hline Allows me to see things work smoothly & 4.54 & Always & 6 \\
\hline Provides me reasonable working hours & 4.34 & Often & 7 \\
\hline Provides me with safe and healthy working environment & 4.72 & Always & 1 \\
\hline Promotes enthusiasm and interest to work & 4.62 & Always & 4 \\
\hline Allows me to observe how the system and processes work & 4.59 & Always & 5 \\
\hline Gives me protection from physical stress & 4.28 & Often & 8 \\
\hline Gives me opportunity to manipulate the needed change & 4.10 & Often & 9 \\
\hline & 4.44 & Often & \\
\hline
\end{tabular}

Legend: $4.21-5.00=$ Always; $3.41=$ Often; $2.61-3.40=$ Sometimes; $1.81 .260=$ Seldom 1.00 -1.80 Never

Table 2 presents the attitude towards the work environment aboard the ship in terms of physical setting. The computed composite mean of 4.44 indicates that it is often observed. Some of the points mentioned are: provides me with a safe and healthy work environment (4.72) and helps me better assess standard work performance (4.67) 
the item promotes the quality of work and promote the efficiency of work (4.64), received and evaluated the highest as usual. The seafarers think and feel about working abroad on cruise as comfortable despite sacrifices and hard work because they are confident that their life would not be at risk and their health would not be compromised. Hence, they work productively because they are content and feel satisfied in their life on sea. A comfortable physical work environment is a concern of the seafarers for it will give them great motivation. If favorable working conditions are lacking, the physical and mental well-being of the seafarers will be badly affected. Factors related to the physical environment such as working hours, temperature, ventilation, hygiene lighting and resources are part of their working condition. If these factors are favorable to them, they will be satisfied with their job performance. Basically, these are factors that influence the motivation of seafarers. The type of environment in which workers work each day - the physical space - can have a significant impact on how people feel about their employment and employers. Comfortable work environments with facilities and rewards that people care about have a big impact on employee morale (Editorial Staff, 2020).

However, items such as protecting me from physical stress, provide the ability to manipulate the necessary changes, and the less rigid elements of the physical placement have the lowest scores of 4.28, 4.10, and 3.95, respectively often observed. Many seafarers reported that poor management of manpower on board ships is the reason for the increase of workload that makes their life hectic. It takes a lot of effort to work in the sea. However, the minimum breaks required by seafarers on board can be overlooked, ultimately leading to extreme fatigue of the seafarers, reducing work efficiency and energy. They are not free from physical stress that is inherent in the kind of task that they do which they cannot manage. This situation makes them flexible enough to adjust in order to cope with the stress. Long and uncertain working hours, according to Raunek (2019), are one of the biggest sources of stress onboard ships. Working challenges that seafarers face, according to him, include a lack of social life, boring routines, and tough working circumstances.

Table 3

Attitude Towards Work Environment Aboard the Ship in terms of Emotional Setting

\begin{tabular}{llll}
\hline Indicators & Weighted Mean & Verbal Interpretation & Rank \\
\hline Stimulates new thoughts and feelings & 4.12 & Often & 10 \\
Encourages me to positively react to situations & 4.34 & Often & 5 \\
Promotes individual control of my environment & 4.19 & Often & 8 \\
Allows me to experience the joy of solitude & 4.19 & Often & 9 \\
Helps me to combat loneliness and homesickness & 4.32 & Often & 6 \\
Gives me a more confident feeling about myself & 4.52 & Always & 1 \\
Makes me a calm and clear-thinking person & 4.44 & Often & 2 \\
Gives me a feeling of security and calmness & 4.44 & Often & 3 \\
Protects me from psychological stress \& disorders & 4.35 & Often & 4 \\
Decreases my fear and inferiority complex & 4.29 & Often & 7 \\
\hline \multicolumn{2}{c}{ Composite Mean } & 4.32 & Often \\
\hline Legend: $4.21-5.00=$ Always; 3.41 = Often; $2.61-3.40=$ Sometimes; $1.81 .260=$ Seldom 1.00 - 1.80 Never
\end{tabular}

Table 3 presents the attitude towards the work environment aboard the ship in terms of emotional setting. The resulting composite mean of 4.32 indicates that it is often observed. The work environment helps me to become a more composed and intelligent individual (4.44), and it makes me feel safe and relaxed (4.44), and shields me from the psychological trauma and inability that comes with being disabled (4.35). There are some ways that make seafarers calm and clear thinking and feel secure. Shore leave is made available to them as a form of relaxation. The Internet facility provides them the opportunity to communicate easily with their families and helps them become aware of the happenings in the world. There is ongoing effective safety training in order to build a real, functioning safety culture so that seafarers are working within a safety management system. Seafarers' life on sea is enjoyable and satisfying if their workplace is a healthy work environment that promotes their well-being and performance, where there is freedom from any tension and conflict, supportive supervision, and an opportunity for advancement. Work, in any form, has a profound effect on emotional and psychological well-being, for better or for worse, especially on the quality and mental health of the work environment. The quality of the work environment has a significant impact on the mental, psychological and physical well-being of employees in all industries. For organizational leaders, paying attention to creating a psychologically healthy 
environment is important not only for the company's health, but also for its employees (Abrams, 2020).

However, items such as promoting individual environmental control allows me to enjoy the pleasures of solitude and stimulates new thoughts and feelings and got the lowest ratings of 4.19, 4.19 and 4.12 respectively. There are some main causes for stress of seafarers on board. Separation from families and friends and concern over leaving loved ones behind cause their loneliness and lonesome feeling on board. This situation sometimes results in a lack of quality sleep and a lack of appetite. These are stressful factors affecting their well-being. However, seafarers can still manage their stress and lonely feelings by enjoying the provision of the internet that gives opportunity for them to connect with families and by participating in some activities. The seafarers can still manage their stress and lonely feelings by enjoying the provision of the internet as an opportunity for them to connect with families and by participating in some activities. Seafarers must look after their mental health while onboard. There are some step-by-step instructions for reducing tension on board and stay calm: By always keeping in mind positive thoughts and do more of what makes them happy; By talking and discussing thoughts as much as possible with others; by taking a breath when feeling pressured to take calm; and by organizing work and spending quality time when off duty (Editorial Team, 2018).

\section{Table 4}

Attitude Towards Work Environment Aboard the Ship in terms of Social Setting

\begin{tabular}{|c|c|c|c|}
\hline Indicators & $\begin{array}{l}\text { Weighted } \\
\text { Mean }\end{array}$ & Verbal Interpretation & Rank \\
\hline Promotes social interaction of individuals & 4.48 & Often & 8 \\
\hline Encourages problem solving and group action & 4.45 & Often & 9 \\
\hline Promotes pleasant and harmonious relationship with people & 4.57 & Always & 5 \\
\hline Allows people to grow socially & 4.50 & Always & 7 \\
\hline Promotes group dynamics and fosters group interaction & 4.36 & Often & 10 \\
\hline Allows to adjust myself with multi-cultured co-workers & 4.58 & Always & 2 \\
\hline Builds up my confidence in dealing with superiors and peers & 4.57 & Always & 3 \\
\hline Fosters good relations and increase my cross-cultural tolerance & 4.50 & Always & 6 \\
\hline Builds up my language and communication skills & 4.59 & Always & 1 \\
\hline Helps me to bring out my leadership abilities & 4.57 & Always & 3 \\
\hline Composite Mean & 4.52 & Always & \\
\hline
\end{tabular}

Legend: $4.21-5.00=$ Always; $3.41=$ Often; 2.61-3.40 = Sometimes; $1.81 .260=$ Seldom 1.00 -1.80 Never

Table 4 presents the attitude towards the work environment aboard the ship in terms of social setting. The resulting composite mean of 4.52 indicates that it is always observed. Among the items cited, it builds up my language and communication skills (4.59), allows me to adjust myself with multicultural workers (4.58), and helps me to bring out my leadership abilities (4.57). Seafarers who have been working on board for a number of years have already learned English as an international language. Because this language is frequently used in the workplace, they have developed their communication skills in their interaction with foreign customers and peers. Their communication skills can boost teamwork and leadership skills essential to better collaboration in implementing a project. When working across different cultural countries and regions, language is a vital consideration, and learning to adapt communication for cultural variations is even more critical when it comes to establishing trust and successful working connections with people all over the world. Individuals can accommodate new surroundings while motivating others to do the same through modifying communication strategies (Cromarty, 2020).

However, Individual social connection is encouraged, as is problem solving and collaborative action, and promoting group dynamics and fosters group interaction got the lowest ratings of $4.48,4.45$ and 4.46 respectively. With effective communication on board, it is established as a conducive environment for the seafarers to think creatively and express their ideas. It helps them feel more comfortable in accommodating challenges and taking initiatives in problem solving. Social interaction is important for one's well-being, which has a favorable effect on employee engagement. Higher levels of employee engagement were associated with better performance results and lower staff turnover. One of the most important components in creating and maintaining a safe atmosphere on and around the vessel is effective communication. This will not only ensure a safer voyage, but also a pleasant crew and miles of sailing pleasure (Gillstrom, 2015). 
Seafarers' attitude and cultural adaptation influencing the work motivation during the time of pandemic

Table 5

Culture Adaptation Aboard the Ship in terms of Communication Skills

\begin{tabular}{|c|c|c|c|}
\hline Indicators & WM & VI & Rank \\
\hline Encourages the employees to apply English language as a standard communication at sea & 4.65 & Always & 1 \\
\hline Trains the employees to practice their English language to improve their communication skills & 4.45 & Often & 5 \\
\hline Exhausts efforts to strengthen provisions concerning Maritime English requirements & 4.36 & Often & 7 \\
\hline Teaches the non-verbal communication to complement spoken English & 4.26 & Often & 10 \\
\hline Exposes the employees to social interactions to avoid being isolated and alienated & 4.34 & Often & 8 \\
\hline Encourages the employees to interact appropriately with people from different cultures & 4.50 & Always & 3 \\
\hline Creates collaborations and good cooperation among mixed-cultured employees & 4.49 & Often & 4 \\
\hline Leads people to learn and know the differences between people who have different cultures & 4.52 & Always & 2 \\
\hline Has broadened mindset \& strategies to handle mixed cultured employees that help to collaborate & 4.44 & Often & 6 \\
\hline Persuades employees to take part in chatting and sharing their feelings & 4.32 & Often & 9 \\
\hline Composite Mean & 4.43 & Often & \\
\hline
\end{tabular}

Legend: $4.21-5.00=$ Always; $3.41=$ Often; $2.61-3.40=$ Sometimes; $1.81 .260=$ Seldom $1.00-1.80$ Never

Table 5 presents the culture adaptation of the respondents aboard the ship in terms of communication skills. The resulted composite mean of 4.43 indicates that it is often observed. Among the items that are always observed are: encouraging the employees to practice their English language to improve their communication skills (4.65), encouraging individuals to learn about and understand the contrasts between people of other cultures and ideas. (4.52) and encouraging the employees to interact appropriately with people from different cultures (4.50). Communication skills help seafarers maintain their relationship with co-workers and clients as well and this generates their job satisfaction. When they are satisfied with their job, there will be stronger teamwork, their participation will be reinforced and that will eventually lead to harmony in the working environment. If everyone puts effort into communicating clearly, the trust among employees can be built. He further reiterates that successful communication increases productivity and brings cohesion among personnel. Hee et al. (2019) emphasizes the importance of effective communication in reaching high levels of performance and sustaining positive working relationships within a business. Effective communication builds a team, increases the performance of employees and reduces the loss of talented and skillful employees in the organization. Cromarty (2020) supports that to work flexibly, one must be adaptable to different cultures and know how to adapt communication for cultural differences.

However, items such as exposing the employees to social interactions to avoid being isolated and alienated, persuading employees to take part in chatting and sharing their feelings and teaching the non-verbal communication to complement spoken English got the lowest rating of 4.34, 4.32 and 4.26 respectively. The importance of sailors getting together in their spare time and the impact that increased physical and mental health has on efficiency and safety. The Social Interaction Matters project of the Seafarers' Welfare and Assistance Network (ISWAN) has identified the following: Social interactions have been shown to be able to improve the mental and physical health and well-being of seafarers with the following clear benefits: Develop the cohesion of the team and improve the resilience that can increase motivation and productivity at sea. Enhanced security practices. Fighting quarantine and liberation from work (Qian, 2020).

\section{Table 6}

Culture Adaptation Aboard the Ship in terms of Interpersonal Relationship

\begin{tabular}{|c|c|c|c|}
\hline Indicators & WM & VI & Rank \\
\hline Provides socio-cultural trainings for and among employees & 4.34 & Often & 4 \\
\hline Encourages employees to socialize in the multicultural environment onboard ship and ashore & 4.31 & Often & 5 \\
\hline Requires employees to have both technical and soft skill competencies & 4.41 & Often & 2 \\
\hline Furnishes capability programs to help employees adapt and adjust in new diversified cultures & 4.29 & Often & 7 \\
\hline Utilizes strategies to assist employees blend in to the work situation aboard & 4.40 & Often & 3 \\
\hline Provides relaxation time and a place for employees to share time and opinion with others & 4.31 & Often & 6 \\
\hline Practices good leadership that benefits employees concerning their work relationship & 4.46 & Often & 1 \\
\hline Issues publication related to socio-cultural study that guides employees & 4.24 & Often & 8 \\
\hline Is proactive in offering its employees lectures and short courses on cultures & 4.15 & Often & 9.5 \\
\hline Requires the employees to possess cultural intelligence before they sign in on a ship & 4.15 & Often & 9.5 \\
\hline & 4.31 & Often & \\
\hline
\end{tabular}

Legend: $4.21-5.00=$ Always; $3.41=$ Often; $2.61-3.40=$ Sometimes; $1.81 .260=$ Seldom 1.00 -1.80 Never 
Table 6 presents culture adaptation aboard the ship in terms of interpersonal relationship. The resulting composite mean of 4.31 indicates that it is often observed. Among the items cited, practicing good leadership that benefits employees concerning their work relationship (4.46), Requiring employees to have both technical and soft skill competencies (4.41) and Utilizing strategies to assist employees blend in to the work situation aboard (4.40). Soft skills such as effective communication, teamwork, leadership and social intelligence among others are all extremely valuable traits of seafarers. Communication is an essential skill that can build relationships between the seafarers, and colleagues carrying out everyday functions at work. Hard skills are technical abilities tied to specific jobs and tasks, and they can be clearly defined and quantified as a result. Education, work experience, knowledge, and level of skill are all things that can be characterized. Soft skills are intangible, non-technical, personality-specific competences that enhance technical competencies and have a great influence on the organizational behaviors, allowing a worker to become a leader, facilitator, mediator, or negotiator (Torre et al., 2019).

However, items like issuing publication related to socio-cultural study that guides employees, being proactive in offering its employees lectures and short courses on cultures, and being proactive in offering its employees lectures and requires employees to possess cultural intelligence before they sign in on a ship got the lowest mean of $4.24,4.15$ and 4.15 respectively. This shows that not much importance is given to seafarers' ability to adapt to the values, beliefs and communication with the people they work with on board. Seafarers commonly developed interpersonal skill during training and experiences. Kapur (2020) found in his study that communications skills are important for any form of business or workplace's success. The ability to relate and operate effectively in culturally varied contexts is referred to as cultural intelligence (CQ). It's the ability to thrive in a variety of cultures across borders. Culturally intelligent individuals are sensitive to the values, beliefs, and communication methods of persons from many cultures. CQ individuals are not cultural experts in all areas. Instead, they have the ability to confidently enter unfamiliar surroundings and make informed decisions based on observations and data.

\section{Table 7}

Seafarers' Work Motivation in terms of Reward System

\begin{tabular}{llll}
\hline Indicators & WM & VI & Rank \\
\hline 1. Makes use of my abilities. & 4.52 & Always & 1 \\
2. Has benefits that are higher compared with those of other firms & 4.18 & Often & 5 \\
3. Provides the employees with chances for advancement on their job & 4.37 & Often & 3 \\
4. Higher compensation compared with those of other workers aboard the ship & 4.14 & Often & 6 \\
5. Gives rapid raise on compensation & 3.96 & Often & 9 \\
6. Considers performance more important than seniority & 4.20 & Often & 4 \\
7. Gives performance bonus better than other companies & 3.94 & Often & 10 \\
8. Recognizes top performing and deserving employees & 4.37 & Often & 2 \\
9. Provides attractive and satisfactory financial remuneration & 4.10 & Often & 7 \\
10. Offers competitive profit sharing, bonus programs, health plans, and etc. & 4.07 & Often & 8 \\
\hline
\end{tabular}

Legend: $4.21-5.00=$ Always; 3.41 = Often; $2.61-3.40=$ Sometimes; $1.81 .260=$ Seldom 1.00 -1.80 Never

Table 7 presents seafarers' work motivation in terms of reward system. The computed composite mean of 4.19 indicates that it is often observed by the respondents. The item that is always observed making use of my abilities (4.52). Items that are often observed, recognizing top performing and deserving employees (4.37) and providing the employees with chances of advancement for their job (4.37). Yuen et al. (2018) discovered that job happiness is strongly linked to seafarer performance in their research. Furthermore, job satisfaction is influenced by the level of stress involved with working on a ship as well as the attractiveness of rewards. Giving the seafarers the chance to apply their special skills in their particular areas will increase their feeling of self-worth that makes them motivated to be more productive in their work. Seafarers are motivated when their accomplishment is recognized because it makes them feel valued for their work. Hence, recognition boosts individual engagement as well as their loyalty that leads to retention of their work. Employee welfare's goals are to improve the working class's quality of life, as well as to promote the holistic development of the worker's character. It allows employees to work in a safe and healthy atmosphere. As a result, it boosts worker 
Seafarers' attitude and cultural adaptation influencing the work motivation during the time of pandemic productivity while also keeping them happy, resulting in excellent employee morale. It also instills in the employees a sense of accountability and dignity.

A well-designed and functional incentive system is an effective way to boost employee motivation at work. Internal sources of motivation include biological and psychological variables, as well as external sources such as rewards, incentives, and goals. To satisfy an employee, the incentives system approach uses both concrete and intangible benefits. According to Yuen (2018), such advantages can include money, bonuses, promotions, training and development, and shipboard welfare. However, items like issuing publication related to socio-cultural study that guides employees, being proactive in offering its employees lectures and short courses on cultures, and being proactive in offering its employees lectures and short courses on cultures got the lowest ratings of 4.24, 4.15 and 4.15 respectively. It is essential for seafarers to be equipped with working knowledge about cultures because this will be a very helpful tool in adapting to the workplace with cultural diversity. This will serve as the bridge to cultural differences and gaps that are present in the workplace. By knowing people's cultures, it is possible to anticipate and predict their behavior. When the seafarer has cultural awareness, has developed a global mindset, practices his language skill, and has a sense of appreciation of cultural differences, he or she is well on his way to successful cultural adjustment. According to Kitada, (2021), the emphasis on cultural awareness is becoming more important, because it facilitates better interaction and greater understanding among the crew, contributing to ship safety.

\section{Table 8}

Seafarers' Work Motivation in terms of Welfare and Opportunity

\begin{tabular}{|c|c|c|c|}
\hline Indicators & WM & VI & Rank \\
\hline 1. Establishes good cruise line education and training system & 4.36 & Often & 9 \\
\hline 2. Supports and values the employees & 4.44 & Often & 4 \\
\hline 3. Has desirable supervisor-subordinate relationship & 4.39 & Often & 8 \\
\hline 4. Practices good internal and external communication & 4.41 & Often & 6.5 \\
\hline 5. Offers good living conditions and working environment onboard & 4.54 & Often & 2 \\
\hline 6. Provides a good balance of working and rest hours to employees & 4.35 & Often & 10 \\
\hline 7. Complies with the national and international regulations related to safety & 4.56 & Always & 1 \\
\hline 8. Accords with the employees' rights and protection & 4.49 & Often & 3 \\
\hline 9. Has high regards for its employees as its asset and be a source of competitive advantage & 4.41 & Often & 5 \\
\hline $\begin{array}{l}\text { 10.Provides the employees with career package which includes comfortable company culture, career path, and } \\
\text { diversity of responsibilities }\end{array}$ & 4.41 & Often & 6.5 \\
\hline Composite Mean & 4.43 & Often & \\
\hline
\end{tabular}

Legend: $4.21-5.00=$ Always; $3.41=$ Often; $2.61-3.40=$ Sometimes; $1.81 .260=$ Seldom $1.00-1.80$ Never

Table 8 presents seafarers' work motivation in terms of welfare and opportunity. The computed composite mean of 4.43 indicates that it is often observed by the respondents. The item that is always observed, complying with the national and international regulations related to safety (4.56), Items that are often observed offering living conditions and working environment on board (4.54) and according with the employees' rights and protection (4.49). Because the shipping companies comply with national and international regulations, the living conditions of seafarers on sea are assured and protected. According to Section 10 of Order No. 784 of the Danish Maritime Authority, "Accommodation and recreational and catering facilities shall meet the applicable requirements on health and safety protection and accident prevention, with respect to perverting risk of exposure to hazardous levels of noise and vibration and other ambient factors and chemicals on board ships and to provide an acceptable occupational and onboard living environment for seafarers". Living conditions of seafarers are favorable based on the findings of Llangco's (2017) study. The findings show that high wages on board can provide a significant benefit because food and lodging are provided for the duration of the contract. Additionally, waiters, cabin workers, and other service workers may be able to significantly raise their salary by taking advantage of passenger gratuities. Because cruise staff are provided with housing and meals as part of their remuneration package, money is only required on board for items such as treats, internet access, phone cards, and anything purchased while off the ship. A career at sea allows you to live comfortably while earning more money.

In the study of Rawat et al., (2015), among the motivational practices for employees are rewards, recognition, training opportunities and career opportunities. However, having desirable supervisor-subordinate 
relationship, package that includes a pleasant work environment, a clear career path, and a wide range of duties and having desirable supervisor- subordinate relationships, establishing good cruise line and got the lowest mean of $4.39,4.36$, and 4.35 respectively.

Employees who believe they have a good relationship with their boss advance faster in their careers, are more committed to their jobs, and are more satisfied with their work. When there is a desirable relationship between the supervisor and the subordinate, the supervisor leads and helps develop the skills of the subordinate. Great company cultures encourage employee participation and provide positive, enjoyable ways for employees to get together for personal and professional development activities both during and outside of regular working hours, and the progress of the company culture is measured by the degree of employee engagement. The findings of Yuen et al (2018) reveal that job happiness is strongly linked to seafarer performance. Furthermore, job satisfaction is influenced by the level of stress involved with working onboard a ship as well as the attractiveness of rewards. Job happiness is also influenced by the attitudes of seafarers and the appeal of the job design.

\section{Table 9}

Difference between the attitude towards work environment aboard the ship when grouped according to profile

\begin{tabular}{|c|c|c|c|}
\hline Age & $\mathrm{U} / \lambda^{2} \mathrm{c}$ & p-value & Interpretation \\
\hline Physical Setting & 13.09 & 0.004 & Significant \\
\hline Emotional Setting & 11.42 & 0.010 & Significant \\
\hline Social Setting & 13.19 & 0.004 & Significant \\
\hline \multicolumn{4}{|l|}{ Civil Status } \\
\hline Physical Setting & 7543.50 & 0.187 & Not Significant \\
\hline Emotional Setting & 8244.00 & 0.711 & Not Significant \\
\hline Social Setting & 7162.50 & 0.064 & Not Significant \\
\hline \multicolumn{4}{|l|}{ Sex } \\
\hline Physical Setting & 12877.50 & 0.032 & Significant \\
\hline Emotional Setting & 13430.50 & 0.116 & Not Significant \\
\hline Social Setting & 13321.00 & 0.090 & Not Significant \\
\hline \multicolumn{4}{|l|}{ Length of Service } \\
\hline Physical Setting & 18.015 & 0.000 & Highly Significant \\
\hline Emotional Setting & 16.607 & 0.001 & Highly Significant \\
\hline Social Setting & 18.167 & 0.000 & Highly Significant \\
\hline
\end{tabular}

Legend: Significant at p-value $<0.05$

When results on attitude toward work environment aboard ship are sorted by profile, the table 9 shows a comparison of responses on attitude towards work environment aboard ship. With the calculated p-values, it was smaller than the alpha level of 0.05 , it was identified that there was a substantial difference when grouped by age and length of service. This means that the responses vary significantly and based on the post hoc test conducted. It was found out that respondents who are 42 to 56 years old and working for more than 10 years have better attitude towards work environment aboard the ship. Moreover, it was highly significant with length of service in terms of physical, emotional, social setting when grouped since they have the mature mindset and are more motivated with their peers working long periods in the cruise line. Also, seafarers' adaptation and emotional development have been an advantage for the seafarer for 10 years.

As the seafarers grow in age and experience their thinking and feeling about their seafaring job is reflected in their behavior in the workplace. They also have developed a set of emotions and beliefs towards their job onboard, over time moments of emotion on the job can influence a person's job satisfaction. As a result of experience, they have developed viewpoints that can have a powerful impact in their physical, emotional and social aspects of behavior toward the work environment. Furthermore, when grouped by sex, there was a significant difference in physical surroundings because the calculated p-value of 0.032 was smaller than the alpha standard. As a result, the responses of male and female vary on the working environment aboard the ship and it was observed that males are given a higher rating initiated together from a different discipline can help improve and inspire colleague working enthusiasm and practices. This can be attributed to the greater number of male respondents than the female respondents. Married men are more likely to focus, motivated on decision making. Similarly, according to Guptan et al. (2017), psychological capital (PsyCap) is a valuable personal resource that helps employees meet their goals. Employees are motivated to engage in extra-role behaviors as a 
Seafarers' attitude and cultural adaptation influencing the work motivation during the time of pandemic

result of this task completion. Chua et al (2017), On impact of individual characteristics on the cruise decision-making process, identified quality factors (i. e, quality of physical environment, quality of interaction, quality of results), satisfaction, emotional involvement. and tried to investigate the interrelationship between., and behavioral intent across gender and age groups. Moderate tests have shown that the route from the quality of the physical environment to the satisfaction of the vacationers and the quality of the results to the satisfaction of the vacationers differ significantly between men and women.

Table 10

Difference responses between the culture adaptation aboard the ship when grouped according to profile

\begin{tabular}{llll}
\hline Age & $\mathrm{U} / \lambda_{\mathrm{c}}^{2}$ & $\mathrm{p}$-value & Interpretation \\
\hline Communication Skills & 1.28 & 0.733 & Not Significant \\
Interpersonal Relationship & 9.14 & 0.027 & Significant \\
\hline Civil Status & & & Not Significant \\
\hline Communication Skills & 8081.00 & 0.553 & Not Significant \\
Interpersonal Relationship & 7841.50 & 0.356 & Significant \\
\hline Sex & & & 0.022 \\
\hline Communication Skills & 12733.00 & 0.756 & Not Significant \\
\hline Length of Service & 14659.00 & & Significant \\
\hline Communication Skills & & 0.015 & Not Significant \\
Interpersonal Relationship & 10.503 & 0.187 & \\
\hline
\end{tabular}

Legend: Significant at p-value $<0.05$

Table 10 shows a comparison of onboard cultural allostasis grouped by profile. The resulting $\mathrm{p}$-value of 0.027 was below alpha level 0.05 , so grouping by age group showed significant differences in interpersonal relationships. This means that the responses vary significantly adapted with culture aboard the ship and based on the post hoc test conducted, it was found out that respondents who are 42 to 56 years old have greater assessment on interpersonal relationships due to their strong personality. This association may be based on interpretation, love, solidarity, regular interactions with other people, or some other type of social commitment. According to Chua et al. (2017), examining the quality of the physical environment, the quality of interactions, the quality of results, satisfaction, emotional attachment, and the strength of the relationship between gender and behavioral intent over age may help you to better understand your behavior.

The data revealed that there was a significant difference on communication skills when grouped according to sex since the obtained p-value of 0.022 was less than the alpha level of 0.05 . This means that the responses vary significantly in speaking and based on the post hoc test conducted, it was found out that respondents who are 42 to 56 years old have a serious assessment on communication skills due to the fact of a long term contract onboard that gives more confidence in speaking. Seafarers believe they have the confidence, potential, skills and intelligence to succeed in the most difficult situations. Confidence increases motivation, reduces anxiety and stress, and increases the likelihood of achievement, career growth, and work relationships.

The results show that the p-value of 0.015 was less than the alpha level of 0.05 , so there was a significant difference in communication skills when grouped by seniority. Therefore, the responses vary significantly to measure the ability of clarity of speaking and based on the post hoc test conducted, it was found out that respondents who are 42 to 56 years old have a considerable assessment on communication skills due to the experience and adaptation of cultural diversity. Effective cultural adaptability makes an individual's ability to differ the communication and management styles of seafarers influenced by their culture and surroundings. According to Kim (2017), the stress-adaptation-growth dynamic governs the process of adjusting to a new culture, a process which is firmly entrenched in the basic human need to attain internal balance in the face of adversity in the environment.

Meanwhile, there was also a significant difference on communication skills when grouped according to sex and length of service since the obtained p-values were less than the alpha level, which means that the responses differ statistically with those male working for more than 10 years having a greater rating on communication skills in the length of services reflecting a stable working environment and have experienced many changes 
within the workplace. After years of interaction with different people in the workplace, seafarers have learned to adopt communication mechanisms for cultural differences to understand and develop a knowledge base, which results in higher productivity. One major personality trait of middle-aged people is agreeableness that reflects the individuals' tendency to develop and maintain prosocial relationships (Shesee \& Graciano, 2021). According to research on interpersonal trust, agreeableness is a key component that leads to trust in others. Agreeability is linked to a number of factors relevant to social harmony motives.

Table 11

Difference responses between the seafarers'work motivation when grouped according to profile

\begin{tabular}{llll}
\hline Age & $\mathrm{U} / \lambda^{2} \mathrm{c}$ & $\mathrm{p}$-value & Interpretation \\
\hline Reward System & 12.21 & 0.007 & Significant \\
Welfare and Opportunity & 20.03 & 0.000 & Highly Significant \\
\hline Sex & & & \\
\hline Reward System & 6282.50 & 0.002 & Significant \\
Welfare and Opportunity & 6131.00 & 0.001 & Highly Significant \\
\hline Civil Status & & & Not Significant \\
\hline Reward System & 13580.00 & 0.157 & Significant \\
Welfare and Opportunity & 12636.50 & 0.016 & Significant \\
\hline Length of Service & & & Highly Significant \\
\hline Reward System & 11.087 & 0.011 &
\end{tabular}

Legend: Significant at p-value $<0.05$

Table 11 illustrates responses on sailors' work motivation when they are categorized by profile. When the participants were categorized by age, a significant difference was noticed, as evidenced by a p-value of 0.007 . Seafarers of different ages in the range have different assessments on the reward system. Middle aged and those in late adulthood seafarers who are supporting their families may be particular with financial rewards such as salary, bonuses and incentives when they are needed most for the benefit of the family. There are some seafarers who value more promotion, career growth and recognition. Based on the computed p-value 0.002, there is significant difference in the assessment of seafarers, when they are categorized according to sex. Male seafarers who are mostly married have already enjoyed benefits, monetary rewards and recognition for their work. This reward system makes them motivated to remain working on board ship, and creates a professional environment at sea while also working in different departments.

When grouped according to sex, the seafarers differ in their assessment on welfare and opportunity based on the computed p-value 0.001. Men and women working on board ships are motivated differently in terms of welfare and opportunity. Women feel undervalued such that they may have low esteem and low self -efficacy than the male counterpart and that they may also be less motivated. The findings in the study of Kahungya (2016), revealed that the VPO provides many sorts of motivation, including compensation, transportation advantages, medical benefits, and advancement. Extra duty allowance, recognition, and assistance for career advancement were also judged to be in short supply, and the package was inadequate. According to Gibson and Parkman (2019), reward power is based on the user's ability to influence others with something of value to them. In leadership positions, individuals use positive reinforcement to influence behaviors with incentives such as praise, recognition, desirable activities, promotions, bonuses or pay rises. In cruise ship setting often individuals are rewarded with opportunities to work in different departments following periods of cross training. Many cruise organizations have employee of the month programmes, where employees can gain recognition and prizes such as half a day off work.

In his research, Llangco (2017) discovered that high profits on board can provide a significant benefit due to the fact that food and lodging are provided for the duration of the contract. Additionally, waiters, cabin workers, and other service personnel can significantly raise their salary by accepting gratuities from passengers. Because cruise staff are provided with lodging and meals as part of their remuneration, money is only required on board for small purchases such as treats, internet access, phone cards, and anything purchased while off the ship. 
Seafarers' attitude and cultural adaptation influencing the work motivation during the time of pandemic

Results show that there is also a significant difference indicated by p-value 0.011 in the assessment of seafarers on the reward system when they are grouped according to their length of service. The longer they are in the service, the longer time they have enjoyed many benefits. Considering seafarers working for more than 10 years, they are more likely to enjoy a salary increase, bonuses, incentives, promotion and gratuities received from customers. Also, their expertise was honed by training and career development they availed from the company. The benefits, services, facilities and amenities provided for their betterment make their life worth living that leads to job satisfaction influencing their work motivation.

From the study conducted by Nabi et al. (2017), they asserted that extrinsic factors such as salary, monetary incentives and compensation packages are great motivators for employees' performance. Relationships with superiors and peers and job security were also important motivators that have a positive effect on the performance of employees. Employees were also shown to be excellent motivators since they believe they have a bright future in their particular organizations. They also discovered that work atmosphere, responsibility, promotion, and recognition, as well as appraisal for completed work, are all elements that influence job enrichment and appraisal. Relationships with superiors, colleagues, and job stability were all indicators of the effects of relationships and security. Growth opportunities affect employees to improve their performance.

There was also a significant difference on welfare and opportunity when grouped according to age indicated by p-value 0.000 . Seafarers of different age levels have different level of motivation when it comes to welfare and opportunity. Of course, they are affected by their attitude toward work and how they adapt to the culture of their workplace. Over and above the money given, employee welfare refers to anything done for the employees' comfort (intellectual or social) improvement. To put it another way, it refers to "efforts to make workmen's lives worth living." It encompasses a variety of services, facilities, and benefits that are provided to employees in order to help them improve their lives. These services may be offered on a voluntary basis or may be required by law. They may be responsible for providing these amenities, or the government or labor unions may do so if they have the necessary liquids. Employees may be motivated by provisional career advancement. The desire to improve their abilities can be a powerful incentive. Employers may provide tuition assistance, send staff to conferences or seminars, or create an in-house skill development program. Employee welfare's objective is to strengthen the working class's quality of life, as well as to promote the holistic development of the worker's personality. It allows employees to work in a safe and healthy atmosphere. As a result, it boosts worker productivity while also keeping them happy, resulting in excellent employee morale. It also instills in the employees a sense of accountability and dignity.

The seafarers also have different perspectives on welfare and opportunity when they are categorized according to civil status since the obtained p-value 0.016 was less than the alpha level. This indicates that the reactions are different statistically and those who are married are more motivated as to welfare and opportunity. This also determined that they are more focused to initiate work and self-directed in their work environment. Menges et al. al (2017), motivation for work performance acts as a source of energy outside of work and relieving stress, as well as provides a strong encouragement that can increase workplace performance. Based on the International Labor Organization (ILO), "employee welfare should be understood as such services, facilities which may be established or in the vicinity of undertakings to enable the persons employed in them to perform their work in healthy and peaceful surroundings and to avail of facilities which improve their health and being high more".

A significant difference in the assessment of welfare and opportunity can also be observed among seafarers when they are grouped according to length of service indicated by p-value 0.00 . Those who are new in the service with less than 10 years of experience will be motivated more to achieve welfare and opportunity benefits than those who are already in the job for longer years because they are already enjoying some of the opportunities. Since this pandemic, there are huge number of experience seafarers who decided to settle down at home and that gives a wide opportunity to the new generation of seafarers. According to Gibson and Parkman (2019), progression is reasonable since it allows individuals to learn and build abilities through a range of 
Rayos, J. L. T., \& Borbon, N. M. D.

training interventions and individual participation.

\section{Conclusion and Recommendation}

The following conclusions were formed as a result of the finding: Work attitude of the respondents towards the work environment is often observed in physical, emotional and social settings. Most seafarers belong within the late early adulthood or young adults and middle adulthood in human life development. They may already be adjusted to their work environment, have experienced challenges and difficulties that they have won over and resolved. They are even more skillful than at an earlier age when they joined the seafaring job. Cultural adaptation aboard the ship through communication skills and interpersonal relationships. The seafarers are culturally adaptable. With their communication skills, they are able to understand, recognize and work effectively within their work environment where there are different cultural norms. Their communication skills lead to a good relationship that in turn improves their work attitude.

Reward system and welfare and opportunity often motivated the respondents. The seafarers have chance to apply their special skills in their particular areas which will increase their feeling of self-worth, making them motivated to be more productive in their work. Seafarers are motivated when their accomplishment is recognized because it makes them feel valued for their work. There is a significant difference in the responses to attitude towards the work environment when responses are grouped according to age and length of service. There is also a significant difference on the responses on physical setting when the respondents are grouped according to sex. There was a significant difference in the responses on interpersonal relationships when the respondents are grouped according to age. There was also a significant difference on the responses on communication skills when respondents are grouped according to sex and length of service. There is a substantial difference on the retorts on seafarers' work motivation when grouped by age, sex and length of service. There is also a significant difference on the responses on welfare and opportunity when the respondents are grouped according to civil status.

The following suggestions are made based on the conclusions obtained: Shipping human resources onboard, may create a supportive and healthy workplace environment (No discrimination) that promotes seafarers' physical and mental health through provision of seafarer amenities, Onboard and offshore programs and activities. They may also provide training for the seafarers' occupational safety, and support them to get the right work-life balance to observe healthy practices that will help them physically and mentally fit to manage their stress, experience job satisfaction, and increase work productivity. Agency employers, may create an adaptive organizational culture where there are trust and healthy working relationships among the seafarers, open and effective communication that bridges mutual understanding between the employer and the seafarers, increase employee's productivity and binds them together, to gain knowledge and understanding of different cultures, accommodate different cultures and adapt communication for culture difference.

Shipping employers, may develop and implement a well-designed and functional reward system that utilizes both tangible and intangible rewards for seafarers' benefits. Reward system must not only satisfy the seafarers but will also increase their feeling of self-worth and boost their work engagement, loyalty, and work commitment, in order to retain seafarers on their job and reduce turnover, they must offer competitive salaries, promote a comfortable workplace environment, provide access to communication facilities, implement reward system at all times, and provide an opportunity for career progression. they may examine in detail the endorsed action plan with careful and critical attention to determine its viability.

For the seafarers to apply their special abilities, they may enhance their hard and soft skills in order to be productive in their work. They must be motivated, focused and resilient. Involving health and wellness activities sessions, read an inspirational book. Strengthening spiritual relationship to the creator, applying practical tips and guidelines on how to be victorious in the industry may be considered. They must also grow in their career and must continue to achieve their goals and objectives. While, for the employers of shipping companies, they may 
Seafarers' attitude and cultural adaptation influencing the work motivation during the time of pandemic

examine in detail the endorsed action plan with careful and critical attention to determine its viability.

To future researchers, they may conduct a related study to discover strategies, techniques, and effective solutions to address the possibilities concerning seafarer work motivation on board with or without crisis. In addition, they may consider other maritime institutions, training centers and tourism and hospitality programs within the Philippines.

\section{References}

Abram, A., (2020). The value of a psychologically healthy workplace. https://www.verywellmind.com/promoting-mental-health-at-work-4175382

Ayap, C. D., \& Macalalad, J. A. (2016). Work values and job satisfaction among seafarers in J-Phil marine incorporated. Asia Pacific Journal of Academic Research in Business Administration, 2(1), 58-72.

Catindig, S. M., Condino, P. A. G., \& Olivares, E. K. S. (2018). Factors that Influence Seafarers' Job Retention as Perceived by Cruise Seafarers from Three Major Cruise Fleets in Manila. LPU-Laguna Journal of International Journal of Tourism and Hospitality Management, 4(2), 1-1.

Chua, B. L., Lee, S., Kim, H. C., \& Han, H. (2019). Investigation of cruise vacationers' behavioral intention formation in the fast-growing cruise industry: The moderating impact of gender and age. Journal of Vacation Marketing, 25(1), 51-70. https://doi.org/10.1177/1356766717750419

Cromarty, C. (2020). How to adapt communication for cultural differences, and why is so important the lugroup.com

Editorial Staff (2021). 11 indicators of a good company culture. BioSpace Sana Biotechnology. Published: Nov 12, 2021. https://www.biospace.com/article/11-indications-of-a-good-company-culture/

Editorial Team (2018). Measuring seafarers'welfare. Safety4sea.com

EMSA. (2020). COVID-19 - Impact on Shipping Report, 13 November 2020. http://www.emsa.europa.eu/newsroom/covid19-impact/download/6306/4055/23.html

Geneva, (2019) https://www.ilo.org/wcmsp5/groups/public/---ed dialogue/---sector/documents/meeting document/wcms 664163.pdf

Gibson, P., \& Parkman R. (2019). Cruise Operation Management. Hospitality Perspectives. Third Edition. Routledge. USA \& Canada.

Gillstrom, K., (2015). Effective Communication on Board. https://currents.bluewatercruising.org/articles/effective-communication-board/

Gorecho, D., R. (2020) Heads the seafarers' division of the Sapalo Velez Bundang Bulilan law offices. https://cebudailynews.inquirer.net/313015/depression-suicide-and-covid-19\#ixzz7E2z3B6I7

Guptan, M., Shaheen, M., \& Reddy, P., K., (2017). Physical, emotional and social aspects of behavior toward the work environment. https://www.emerald.com/insight/content/doi/10.1108/JMD-06-2016-0084/full/html

Hee, O. C., Qin, D. A. H., Kowang, T. O., Husin, M. M., \& Ping, L. L. (2019). Exploring the impact of communication on employee performance. International Journal of Recent Technology and Engineering, 8(3), 654-658.

Heider's (2015) Theory of attitude organization. GK Today Retrieved August 28, 2021 from gktoday.in. https://www.gktoday.in/topic/theories-of-attitude-organization/

Kahungya, E., F. (2016). Effects of motivation on employees performance: A case study of vice president's office in Dar Es Saalam. Open University of Tanzania.

Kapur, R. (2020). Communication skills for workplace success. University of Delhi.

Kim, Y. Y. (2017). Cross-cultural adaptation. In Oxford Research Encyclopedia of Communication. https://doi.org/10.1093/acrefore/9780190228613.013.21

Kitada, M. (2021). Women seafarers: Analysis of barriers in their employment. World Maritime University, Milan.

Llangco, M. O (2017). Filipino seafarers on-board cruise ships: Shared viewpoints on working lives. Seafarers International Research Center. 
Rayos, J. L. T., \& Borbon, N. M. D.

Lumen Learninng (2018). "Psychology Thoughts." Provided by: Pixabay. Located at https://pixabay.com/en/head-psychology-thoughts-think-2032751/

Mejia, R. L. (2021). An Evaluation on the Culture Adaptation and Attitude Towards Work Environment Aboard the Ship, Asia Pacific Journal of Management and Sustainable Development 9(2), 100-110.

Menges, J. I., Tussing, D. V., Wihler, A., \& Grant, A. M. (2017). When job performance is all relative: How family motivation energizes effort and compensates for intrinsic motivation. Academy of Management Journal, 60(2), 695-719. https:// doi.org/10.5465/amj.2014.0898

Nabi, N. et al. (2017). The impact of motivation on employee performances: A case study of Karmasangsthan. Book Limited, Bangladesh.

Patinio, F. (2021) Republic of the Philippines News Agency https://www.pna.gov.ph/articles/1145024

Pauksztat, B., Grech, M., Kitada, M., and Jensen, R. B. (2020). Seafarers' experiences during the COVID-19 pandemic: Report. https://doi.org/10.21677/wmu20201213

Qian, X., Ren, R., Wang, Y., Guo, Y., Fang, J., Wu, Z. D., ... \& Members of Steering Committee, Society of Global Health, Chinese Preventive Medicine Association. (2020). Fighting against the common enemy of COVID-19: a practice of building a community with a shared future for mankind. Infectious Diseases of Poverty, 9(02), 8-13. https://doi.org/10.1186/s40249-020-00650-

Raunek (2019). 12 main reasons seafarers quit sea jobs. Life at Sea- Marine Sight marinesight.com.

Rawat, B., Khugshal, R., \& Chaubey, D. S. (2015). Employee attitude towards motivational practices: an empirical study. Global Management Review, 9(2), 14-28.

Shesee, B.E. \& Graziano, W. G. (2021). Agreeablleness. Encyclopedia of Applied Psychology sciencdricet.com

Smith, J. (2018). Working on a cruise ship. Retrieved from https://www.prospects.ac.uk/jobs-and-workexperience/job-sectors/leisure-sport-and-tourism/working-o n-a-cruise-ship

Talmor, P. (2020). Careers at sea: Exploring seafarers'motivation s and aspirations. The World of the Seafarers pp.51-63

Torre, M., Giannoni, M. \& Colzine, G. (2019). Investigating seafarers' hard and soft skills in maritime logistics: an orveraching approach. Impresa Progretto Electronic Journal of Management

Yuen, K. F., Loh, H. S., Zhou, Q., \& Wong, Y. D. (2018). Determinants of job satisfaction and performance of seafarers. Transportation research part A: policy and practice, 110, 1-12. 